\title{
Consultant psychotherapists: who needs them?
}

\author{
Clare Adams \& Maria O’Kane
}

Ir J Psych Med 1999; 16(2): 41-42

"The idea of a psychotherapeutically informed psychiatry seems such a simple and obvious one and yet the divide between psychotherapy and general psychiatry - between 'brainlessness' and 'mindlessness' has, until recently, seemed unbridgeable".'

The Psychotherapy section of the Royal College of Psychiatrists has the largest membership in the college. Since psychotherapy became recognised as a discipline within psychiatry in 1975 the Royal College of Psychiatrists has recommended one consultant psychotherapist for each 200,000 of the population. In Northern Ireland there are only 1.9 whole time equivalents rather than the eight expected and in the Republic of Ireland there is none. According to the recent document produced by the Royal College of Psychiatrists' Psychotherapy Faculty Executive Committee in December 1998, The development of psychological therapy services: Role of the consultant psychotherapist, ${ }^{2}$ there has been no net growth in the last five years in the numbers of psychotherapists in England and Wales. The future looks equally gloomy in Ireland.

This is rather surprising given that recent government documents have highlighted both the importance and the effectiveness of psychological therapies. ${ }^{3,4}$ There is a growing evidence base underpinning the use of psychotherapy in the management of a wide variety of conditions including psychoses, eating disorders and severe personality disorders.

Psychotherapy has high public acceptability and finds itself in the unusual position of having both government and public demanding the provision of extra psychological therapies, but not receiving the full support of psychiatry and the purchasers of healthcare.

Psychiatrists have always undertaken the roles of advocate and agent for patients but by not demanding a psychotherapeutic basis to our treatments, we are failing them and providing a second rate service. Research has shown that psychological treatments are as efficacious and as cost-effective as drug treatments. ${ }^{3}$ In addition psychological treatments are a powerful adjunct to medication in the maintenance therapy of schizophrenia and are the treatment of choice in other severe disorders such as eating disorders and severe personality disorders. Thus within the public sector we are practising rationing by diagnosis, by providing the biological treatments for some conditions in preference to the psychological treatments for others.

"Clare Adams, MB, MRCPsych, Consultant Psychotherapist, Department of Psychotherapy, 100 King's Road, Belfast, BT5 $7 \mathrm{BW}$, Northern Ireland.

Maria O'Kane, MB MRCPsych, Senior Registrar in General Psychiatry and Psychotherapy, 100 King's Road, Belfast, BT5 $7 \mathrm{BW}$, Northern Ireland.

* Correspondence

SUBMIT TED: MAY 10, 1999. ACCEPTED: MAY 20, 1999.
Thereby we undervalue our own service and the benefits we can deliver.

Since 1993, psychotherapy training for juniors has been a mandatory requirement of training in general adult psychiatry and may become a mandatory requirement of the MRCPsych examination. Repeated surveys have underlined trainees' desire for training but dissatisfaction with the quality of this training and supervision..$^{5,6,7}$ They feel unskilled in the use of psychotherapeutic assessments and interventions despite having a high expectation of becoming proficient in these skills when they commence training in psychiatry.

The quality of training is now under very close scrutiny in the new 'Calman' era and psychotherapy training is in fact one of the few areas where training standards have been provided. ${ }^{8}$

This raises questions about the profession's own resistances to the development of services within the public sector despite the evidence of their effectiveness.

Attitudes in general psychiatry to psychotherapy vary from viewing it as something that every psychiatrist inherently does anyway despite lack of training and evidence to the contrary, to a belief that it is all 'magical nonsense' which no one can understand or readily apply in every day practice.

Likewise psychotherapists have cut themselves off from the distractions of general psychiatry to become more focused on their own work and thus less available to general psychiatry. Indeed specialist psychotherapy services may have inadvertently colluded with this by becoming ivory towers with relatively little interaction with other parts of psychiatry. This exclusiveness may have contributed to the myth that only patients who are 'nearly well' are suitable for any form of psychotherapeutic intervention. This sense of a special treatment for special patients blocks psychotherapy from becoming fully integrated into the general psychiatrist's treatment armament for patients. This artificial dichotomy in approach has done psychiatry and our patients a disservice.

This is against a background of increasing demand for a growing number of psychotherapeutic interventions which have become available in the private sector. There is a sense that 'psychotherapy is a luxury the public sector cannot afford' and that it is acceptable that those who can pay for it have access to a variety of treatments, but those who cannot pay do not receive it. ${ }^{9}$

The role of psychotherapy is changing within the public health service. Psychotherapy is a core discipline for all psychiatrists, deepening the understanding of the doctorpatient relationship and providing vital insights into the emotional life of patients. Not all patients who attend a psychiatrist will require psychotherapy per se but all will benefit from psychotherapeutically informed practice. Psychotherapy can no longer exist in isolation and general 
psychiatry can no longer afford to ignore psychotherapy.

Much of the recent literature outlining a modern psychiatry and psychotherapy service emphasises the proven effectiveness of the integrated hub and spoke model, involving experts disseminating knowledge by training, supervision and consultation with others throughout the psychiatric system. ${ }^{10,11}$ This approach complements the need to widen the availability of psychotherapy and the requirement to co-ordinate services into primary, secondary, tertiary and area level services.

However to lead psychotherapy services into the next millennium, consultant psychiatrists in psychotherapy need to be trained.

The consultant psychotherapist has a key role to play in education and support, in providing training, supervision, expertise, leadership and containment. They are ideally placed to offer expert opinions, insights and liaison to individuals and organisations to help them in making the complex simple, based on an additional body of theory, experience and skills.

They are responsible for the maintenance of professional standards within their own teams. The consultant has professional autonomy which may be 'delegated but not abrogated' and is legally ultimately responsible for determining diagnosis and the prescription of specific treatments. ${ }^{2}$

The training of consultant psychotherapists has to be considered in terms of benefits and opportunity costs to the individual and to the service. Psychotherapists are not born, they are trained. Expertise in psychotherapy requires time, training and money. It is intensive and relatively more costly then general psychiatric training, but in reality it should be viewed as a long-term investment in the service, producing dividends in expertise, especially in dealing with more disturbed patients, and in teaching, training and supervision. ${ }^{12}$ Although finance is often put forward as the main obstacle, no one queries the need to train experts in other disciplines, such as key-hole surgeons, who cost as much yet probably are not as clear an investment in the health service.

The Department of Psychotherapy in Belfast has the only Specialist Registrar post approved for training in the whole of Ireland. There have been only three graduates from this system in the last 15 years. There are currently three senior trainees completing dual Certificates of Specialist Training in Adult Psychiatry and Psychotherapy. This training has relied heavily on private sector and university course training models.

Staff as well as patients benefit from psychotherapeutically informed practice. Psychotherapy brings with it a body of knowledge and approach which helps in simplifying difficult concepts but does not make them less important or 'just common sense'. Importantly, general psychiatry should be able to perceive tangible improvements with the integration of psychotherapeutic interventions. Psychotherapeutic theory and practice should no longer be viewed as too complex and diverse to merit knowledge and understanding in the real world or too obvious and straightforward to merit separate training and expertise.

The patients we are asked to treat have increasingly complex problems. Less complicated cases no longer reach psychiatry and psychotherapy services as their difficulties have been resolved in primary care settings. For the more severely ill there are no quick fixes. We all believe and evidence shows that the most complex cases are best dealt with by those with training and expertise. We do psychiatry and our patients a disservice if we undermine our own specialty by denying ourselves training and access to expertise through psychotherapy training.

The integration of psychotherapy and psychiatry services has implications for training and service. The consultant psychiatrist in psychotherapy in the new millennium will have a more defined role in treatment, supervision and support and in helping to understand organisations and the individuals who comprise them.

"Psychotherapeutically informed psychiatrists need to make the case for investment in interpersonal technology no less cogently than physicians and surgeons clamour for bigger and better machines".

\section{References}

1. Eisenberg L. Mindlessness and brainlessness in psychiatry. $\mathrm{Br} \mathrm{J}$ Psychiatry $1986 ; 148: 497-508$.

2. Royal College of Psychiatrists' Psychotherapy Faculty Executive Committee. The development of psychological therapy services: role of the consultant psychotherapist. London: Royal College of Psychiatrists, December 1998.

3. Department of Health NHS Psychotherapy Services in England: Review of Strategic Policy. London: HMSO, 1996.

4. Roth A, Fonagy P. What works for whom?: a critical review of psychotherapy research 1996 New York: Guildford Press, 1996.

5. Davies SP. Psychotherapy Training on a shoestring: improving training using existing resources. Psychiatr Bull 1998; 22(11): 702-6.

6. Hwang KS, Drummond LM. Psychotherapy training and experience of successful candidates in the MRCPsych exams. Psychiatr Bull 1996; 20(10): 604 .

7. Morton M, Bailey J. A survey of psychotherapy training among psychiatric trainees. Psychiatr Bull 1996: 20(9): 536-8.

8. Grant S, Holmes J, Watson J. Guidelines of psychotherapy training as part of general professional training. Psychiatr Bull 1993; 17:856-9.

9. Marks I. Psychotherapy - a luxury the NHS cannot afford? BMJ 1992; 309 1071-2.

10. Holmes J, Mitchison S. A model for an integrated psychotherapy service. Psychiatr Bull 1995; 19(4): 209-13.

11. Holmes J. The integration of psychiatry and psychotherapy. Psychiatr Bull $1995 ; 19(8): 465-6$.

12. MacDonald AJ. Training and outcome in supervised individual psychotherapy. Br J Psychotherapy 1992; 8(3): 1992. 


\section{ABBREVIATED PRESCRIBING INFORMATION: PROVIGILA}

Please refer to summary of product characteristics before prescribing.

Presentation: White to off-white tablets each containing modafinil $100 \mathrm{mg}$. Indication: Narcolepsy. Dosage: Adults: $200-400 \mathrm{mg}$ daily either as two divided doses in the morning and at noon or as a single morning dose according to response. Elderly: Treatment should start at $100 \mathrm{mg}$ daily which may be increased subsequently to the maximum adult daily dose in the absence of renal or hepatic impairment. Severe renal or hepatic impairment: Reduce dose by half (100-200 mg daily). Children: Not recommended. Contra-indications: Pregnancy, lactation, hypersensitivity to modafinil or any excipients used in Provigil. Warnings and precautions: Patients with major anxiety should only receive Provigil treatment in a specialist unit. Patients should be advised to notify their physician if they become or intend to become pregnant during therapy. Blood pressure and heart rate should be monitored in hypertensive patients. Provigil is not recommended in patients with a history of left ventricular hypertrophy or ischaemic ECG changes, chest pain, arrhythmia or other clinically significant manifestations of mitral valve prolapse in association with CNS stimulant use. Studies of modafinil have demonstrated a low potential for dependence although the possibility of this occurring with long-term use cannot be entirely excluded. Drug interactions: Induction of cytochrome P-450 isoenzymes has been observed in vitro. contraception, a product containing at least $50 \mathrm{mcg}$ ethinyloestradiol should be taken. Tricyclic antidepressants - no clinically relevant interaction was seen in a single dose interaction study of Provigil and clomipramine. However, patients receiving such medication should be carefully monitored. Care should be observed with co-administration of anticonvulsant drugs. Side effects: Nervousness, excitation, aggressive tendencies, insomnia anorexia, headache, CNS stimulation, abdominal pain, dry mouth, palpitation, tachycardia and tremor have been reported. Nausea and gastric discomfort may occur and may improve when tablets are taken with meals. Pruritic skin rashes have been observed occasionally. Buccofacial dyskinesia has been reported very rarely. Marketing authorisation number: PA $827 / 1 / 1$. Marketing authorisation holder: Cephalon UK Ltd., 11/13 Frederick Sanger Road, Surrey Research Park, Guildford, Surrey GU2 5YD, UK. Legal category: POM. Date of preparation: July 1998. Provigil and Cephalon are registered trademarks.

References: 1. Mitler MM. Sleep 1994; 17: S103-S106. 2. Data on file, Cephalon [676] 3. Lin JS et al. Proc Natl Acad Sci USA 1996; 93 (24): 14128-14133. 4. Simon P et al. Eur Neuropsychopharmacol 1995; 5: 509-514.

Medical Information Department Freefone no.

1800535669 and e-mail ukmedinfo@cephalon.com

Ge Cephalon

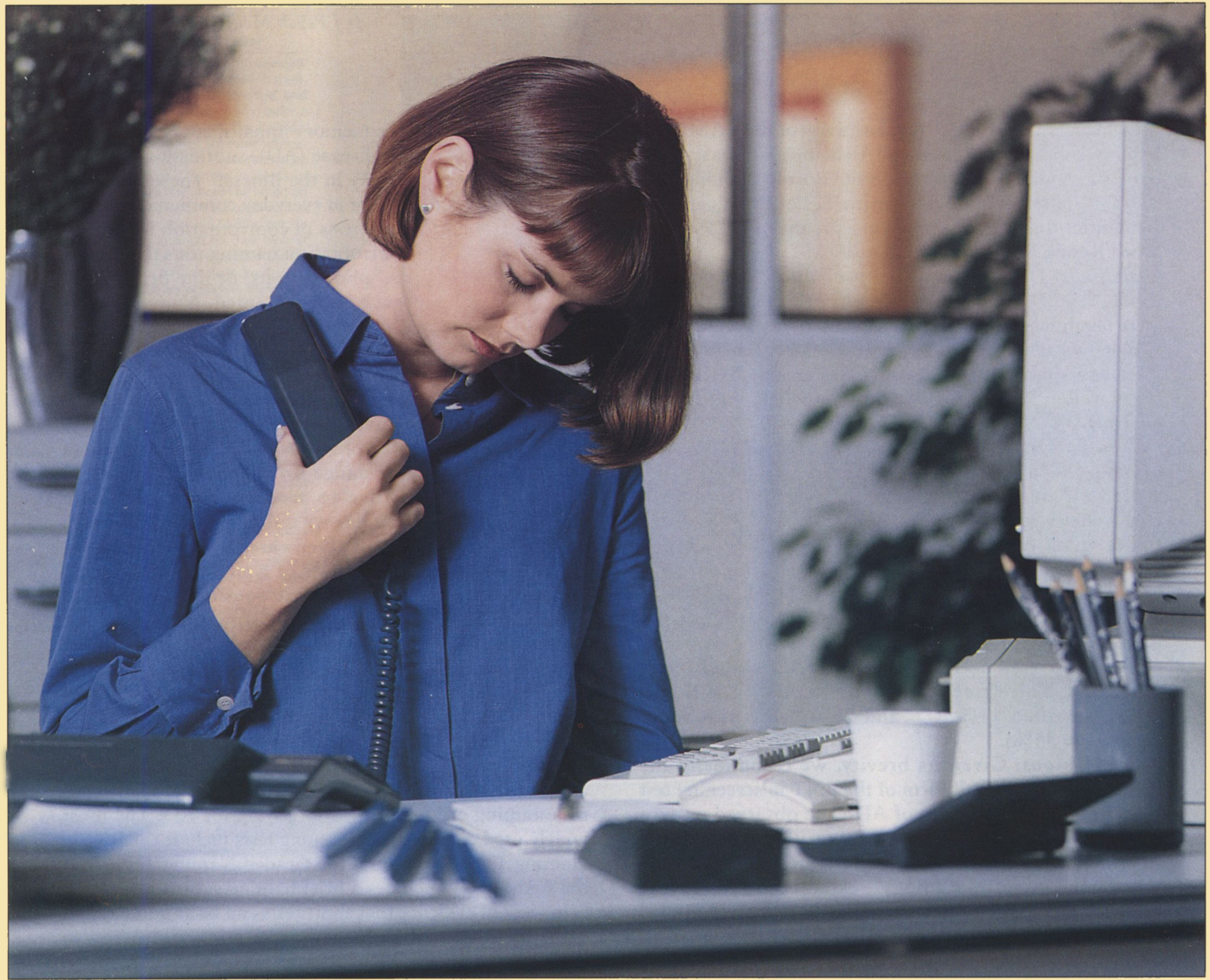

\section{WAKE UP LITTLE SUZIE, WAKE UP}

Excessive sleepiness associated with narcolepsy frequently has a disastrous effect on patients' lives, by impairing their physical, social and emotional well being. Unfortunately, treatment with amphetamines is often associated with a high incidence of unpleasant side effects, which limit their overall benefit.'

Now Provigil (modafinil) - a novel wake promoting agent - offers new advantages in narcolepsy. The clinical efficacy of Provigil has been demonstrated in large controlled clinical studies. In one study, ${ }^{2}$ one in five people with severe narcolepsy reached normal levels of daytime wakefulness while receiving Provigil.

Provigil activates the CNS in a more selective manner than amphetamine and related agents $^{3}$ and differs greatly from this group of drugs in its pharmacology. ${ }^{4}$ Consequently the incidence of amphetamine like side effects is very low.

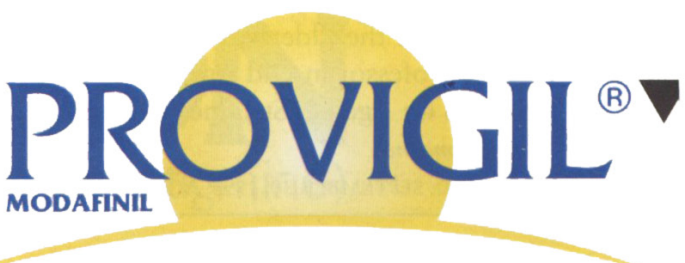

A NOVEL, NON AMPHETAMINE WAKE PROMOTING AGENT 